\title{
Sex-related differences in patients undergoing radiofrequency ablation of atrioventricular nodal reentrant tachycardia
}

\author{
Joanna Sokołowska1, ${ }^{1}$ Magdalena Sokołowska ${ }^{2}$, Jakub Adamowicz² ${ }^{\oplus}$,

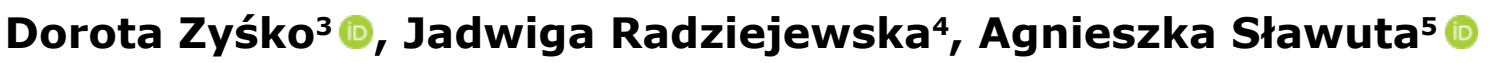

\author{
${ }^{1}$ Praxis Joanna Sokołowska, Ingolstadt, Germany \\ ${ }^{2}$ Department of Cardiology, Kłodzko County Hospital, Kłodzko, Poland \\ ${ }^{3}$ Department of Emergency Medicine, Wrocław Medical University, Wrocław, Poland \\ ${ }^{4}$ Kłodzko County Hospital, Kłodzko, Poland \\ ${ }^{5}$ Department of Internal and Occupational Diseases, Hypertension and Clinical Oncology, \\ Wrocław Medical University, Wrocław, Poland
}

\begin{abstract}
Background: Atrioventricular nodal reentry tachycardia (AVNRT) is the most common paroxysmal supraventricular tachycardia. The relatively ineffective antiarrhythmic drugs and the predominant young age makes the catheter ablation the therapy of choice in many patients. This results in predominance of this arrhythmia in electrophysiological labs. The aim of the study was to analyze the gender-related differences among patients undergoing the radiofrequency catheter ablation of slow pathway entrance to the atrioventricular node. Material and methods: The study group comprised of 147 consecutive patients with diagnosed atrioventricular nodal reentry tachycardia, who underwent the radiofrequency catheter ablation (RFCA) of slow pathway. Patients have been divided into 2 groups, based on sex. Results: The overall $97.3 \%$ of effectiveness of RFCA was observed. Women were significantly younger than men $(53.7+/-17.2$ vs. $57.7+/-9.8$ years) with lower radiation dose $(2383.5+/-1993.2$ vs. $2891.6+/-2377.1$ cGyxcm2). Conclusions: Younger age of women in comparison to men during RFCA of AVNRT reflects earlier onset of symptoms in women. Gender does not affect the time of fluoroscopy, but the higher rate of inducible tachycardia after RFCA in women may suggest the existence of anatomical difficulties or the operator's apprehensions. Sex-related difference in radiation dose that we have observed may result from the greater volume of the men's chest.
\end{abstract}

Keywords: bariatric surgery $\cdot$ metabolic surgery $\cdot$ BAROS $\cdot$ SF-36 $\cdot$ QoL

\section{Citation}

Sokołowska J, Sokołowska M, Adamowicz J, Zyśko D, Radziejewska J, Sławuta A. Sex-related differences in patients undergoing radiofrequency ablation of atrioventricular nodal reentrant tachycardia. Eur J Transl Clin Med. 2019;2(2):19-22. DOI: $10.31373 /$ ejtcm/115072 


\section{Introduction}

Atrioventricular nodal reentry tachycardia (AVNRT) is the most common type of paroxysmal supraventricular tachycardia, accounting for approximately $60 \%$ of all narrow-QRS-complex tachycardias [1-2]. AVNRT is up to 4 times more likely to affect women than men and tends to appear in young patients (mean age of 32 years) [2-4]. The reentrant mechanism of this arrhythmia results from the existence of the 'fast' and 'slow' atrioventricular nodal entry pathways, differing in conduction velocity and refractory period [5]. Due to the relatively ineffective antiarrhythmic pharmacotherapy and the predominant young age of the patients, catheter ablation continues to be considered the treatment of choice [6]. This method was introduced in 1982 by Gallagher et al [7]. The slow pathway ablation is a highly-effective method, with a success-rate of over 91$95 \%$, minor recurrence index and a very low complication rate of $0.2-0.7 \%$ [8-9].

The recommended invasive treatment resulted in AVNRT being one of the dominant clinical entities treated in electrophysiology labs and could influence the change in the patient population. The prevalence of this arrhythmia also contributed to better training of the physicians performing the ablation procedures. Moreover, the newly available techniques, such as cryoablation, could change the electrophysiologists' attitude toward the endpoints of the first ablation, in particular in younger patients. We further hypothesize that the patient's characteristics and effective results assessment have changed along with an increased number of performed ablation procedures.

\section{Aim}

The aim of the study was to analyze the gender-related differences among patients undergoing the radiofrequency catheter ablation (RFCA) of slow pathway entrance to the atrioventricular node.

\section{Materials and methods}

The study group comprised of 147 consecutive patients with diagnosed atrioventricular nodal reentry tachycardia, who underwent the RFCA of slow pathway between January 2012 and December 2017. Standard RFCA was performed using one diagnostic decapolar deflectable catheter located in the coronary sinus. We used $4 \mathrm{~mm}$ tip, non-irrigated, radiofrequency catheters for His-bundle location and the procedure itself. The temperatures were initially set for $52^{\circ}$ Celsius (C) and then increased to $56-58^{\circ} \mathrm{C}$. The RF ablation was pre- ceded by an electrophysiological study aiming at the assessment of the properties of the atrioventricular junction and implicitly at the induction of the AVNRT. The procedure was performed in the presence of dual atrial echoes during programmed atrial pacing on patients with a clinically confirmed arrhythmia, after excluding an accessory pathway. The ablation process was aimed to change the electrophysiological properties of the slow pathway eventually to total elimination of the slow pathway conduction. Clinically, the purpose of the procedure was the non-inducibility of the arrhythmia or profound changes to the AV junction properties which could prevent the tachycardia recurrence.

Patients were divided into 2 groups based on sex. Parameters, such as age, cycle length duration, Wenckebach point, time of fluoroscopy, the radiation exposure and effect of the procedure were analyzed. The effect of the procedure was rated based on the scale presented in the table 1 . The analyzed parameters are presented as the means and standard deviations. Assessment of the statistical significance was performed using the non-parametric Mann-Whitney $U$ Test. P value $<0.05$ was considered statistically significant.

Table 1. Assessment of the radiofrequency catheter ablation of slow pathway entrance to the atrioventricular node procedure efficacy

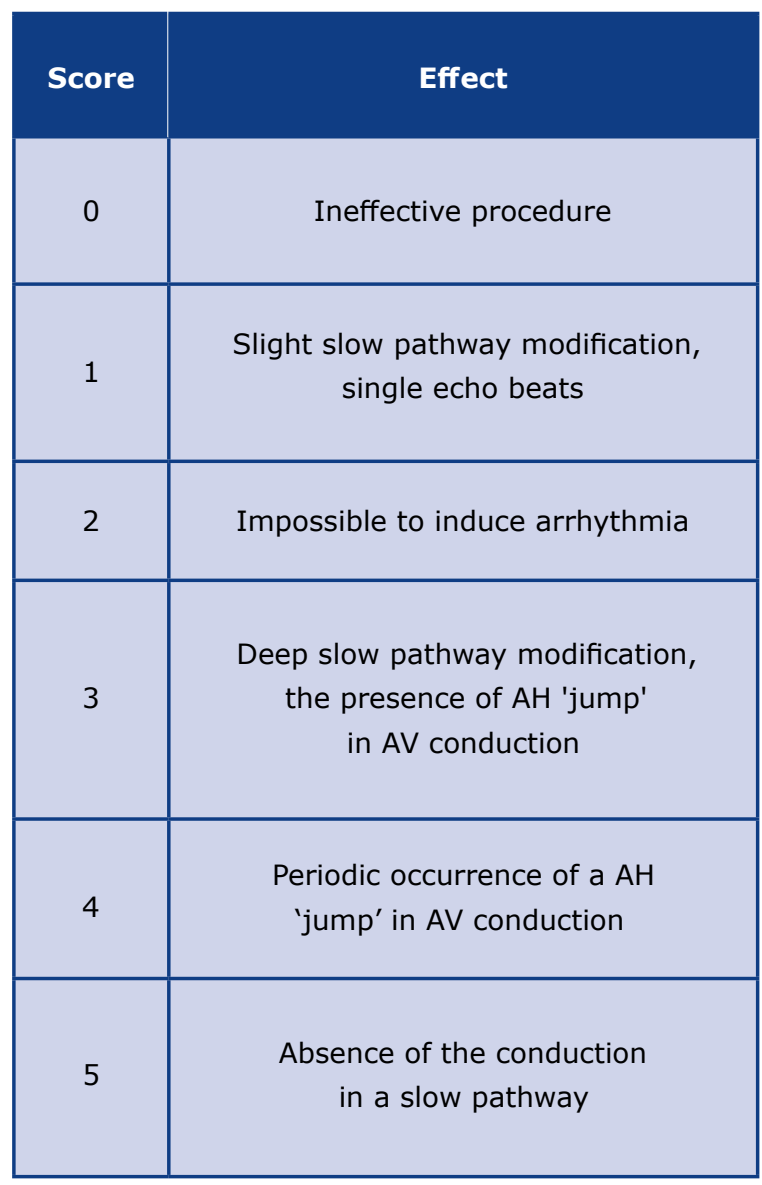

AV - atrioventricular 


\section{Results}

The clinical and procedural characteristics of the studied patients were presented in table 2 .

In 4 cases - all female patients the non-inducibility of the tachycardia could not be obtained; there was no such case among men. The overall $97,3 \%$ of effectiveness was observed. Women were significantly younger than men $(53,7+/-17,2$ vs. $57,7+/-9,8)$ with lower radiation dose $(2383,5+/-1993,2$ vs. 2891,6 $+/-2377,1$ ). We did not observe any statistically significant sex-related differences among the patients within the other parameters.
Suenari et al. women were also significantly younger than men [16]. The above-mentioned study by Liuba et al. showed however the differences in age of patients with heart disease and with lone AVNRT.

Associated heart disease was present in patients who experienced the first episode of tachycardia at a significantly older age (women $50+/-18$ and men $45+/-20$ ) what more precisely reflects the features of our population [14]. The differences in AV conduction properties are probably the reason of different incidence of AVNRT [16]. In women Wenckebach block point was lower than in men. The same results presented Liu et al. in study on sex differences in AV conduction [17].

Table 2. The analyzed parameters in the patient sample

\begin{tabular}{|c|c|c|c|c|}
\hline & $\begin{array}{l}\text { Women } \\
(n=104)\end{array}$ & $\begin{array}{c}\text { Men } \\
(n=43)\end{array}$ & $\begin{array}{l}\text { All patients } \\
(n=147)\end{array}$ & P value \\
\hline Age (years) & $53.7 \pm 17.2$ & $57.7 \pm 9.8$ & $55.2 \pm 14.9$ & $p<0.05$ \\
\hline Cycle length (ms) & $381.2 \pm 74$ & $377.2 \pm 58.3$ & $380.3 \pm 70.4$ & n.s \\
\hline Wenckebach point (ms) & $377.1 \pm 78.3$ & $389.4 \pm 80.9$ & $390.5 \pm 79.5$ & n.s \\
\hline Fluoroscopy (s) & $335.5 \pm 229.2$ & $338.3 \pm 187.4$ & $336.3 \pm 217.2$ & n.s \\
\hline $\begin{array}{l}\text { Radiation dose } \\
(\mathrm{cGy} \times \mathrm{cm} 2 \text { ) }\end{array}$ & $\begin{array}{c}2383.5 \pm \\
1993.2\end{array}$ & $\begin{array}{c}2891.6 \pm \\
2377.1\end{array}$ & $\begin{array}{c}2532.2 \pm \\
2117.1\end{array}$ & $p<0.05$ \\
\hline $\begin{array}{c}\text { Effect of the } \\
\text { procedure (scale) }\end{array}$ & $3.0 \pm 1.3$ & $3.2 \pm 1.0$ & $3.1 \pm 1.2$ & n.s \\
\hline
\end{tabular}

\section{Discussion}

RFCA is a highly successful method in both men, and women. According to the literature, women experience more symptoms than men, but they have longer time of delay before ablation [10-11]. Carnlöf et al. showed, that $17 \%$ of women stated that they were not taken seriously (vs. 7\% men) and were misdiagnosed more frequently as suffering from panic disorders [1213]. According to the results of Liuba et al. acute success rate and the recurrence rate were similar in both sexes, although some authors claim that women are more likely have certain arrhythmia symptoms after the procedure [14]. In our study, women undergoing RFCA were younger than men, what can be explained by the earlier onset of symptoms in women. This association was documented by Deneke et al. with onset of symptomatic AVNRT at age of $38+/-18$ in women vs. $51+/-18$ years in men $(p=0.01)$ [15]. In the study
The duration of fluoroscopy did not differ between sexes, but there was a difference in radiation exposure between men and women. Those results are similar to earlier studies and most probably should be attributed to the patients' body dimensions and the default settings of fluoroscopy $[10,16,18]$.

\section{Conclusions}

Younger age of women in comparison to men during RFCA of AVNRT reflects earlier onset of symptoms in women. Sex does not affect the time of fluoroscopy, but the higher rate of inducible tachycardia after RFCA in women may suggest the existence of anatomical difficulties or the operator's apprehensions. Sex-related difference in radiation dose that we have observed may result from the greater volume of the men's chest. 


\section{References}

1. Katritsis DG, Camm AJ. Atrioventricular nodal reentrant tachycardia. Circulation. 2010;122(8):831-40. Available from: https://doi.org/10.1161/CIRCULATIONAHA.110.936591

2. Porter MJ, Morton JB, Denman R, Lin AC, Tierney S, Santucci PA, Cai JJ, Madsen N, Wilber DJ. Influence of age and gender on the mechanism of supraventricular tachycardia. Heart Rhythm. 2004;1(4):393-6. Available from: https://doi. org/10.1016/i.hrthm.2004.05.007

3. Lang F. Encyclopedia of molecular mechanisms of disease. Springer Science \& Business Media; 2009.

4. Goyal R, Zivin A, Souza J, Shaikh SA, Harvey M, Bogun F, Daoud E, Man KC, Strickberger SA, Morady F. Comparison of the ages of tachycardia onset in patients with atrioventricular nodal reentrant tachycardia and accessory pathway-mediated tachycardia. Am Heart J. 1996;132(4):765-7. Available from: https://doi.org/10.1016/S00028703(96)90308-7

5. Jackman WM, Beckman KJ, McClelland JH, Wang X, Friday KJ, Roman CA, Moulton KP, Twidale N, Hazlitt HA, Prior $\mathrm{MI}$, et al. Treatment of supraventricular tachycardia due to atrioventricular nodal reentry by radiofrequency catheter ablation of slow-pathway conduction. N Engl J Med. 1992;327(5):313-8. Available from: https://doi.org/10.1056/ NEJM199207303270504

6. Katritsis DG, Zografos T, Katritsis GD, Giazitzoglou E, Vachliotis V, Paxinos G, Camm AJ, Josephson ME. Catheter ablation vs. antiarrhythmic drug therapy in patients with symptomatic atrioventricular nodal re-entrant tachycardia: a randomized, controlled trial. Europace. 201;19(4):602-606. Available from: https://doi.org/10.1093/europace/euw064

7. Gallagher JJ, Svenson RH, Kasell JH, German LD, Bardy GH, Broughton A, Critelli G. Catheter technique for closed-chest ablation of the atrioventricular conduction system. N Engl J Med. 1982;306(4):194-200. Available from: https://doi. org/10.1056/NEJM198201283060402

8. Yaminisharif A, Davoodi G, Kasemisaeid A, Farahani AV, Ghazanchai F, Moghaddam M. Radiofrequency Catheter Ablation of Atrioventricular Nodal Reentrant Tachycardia: Success Rates and Complications during 14 Years of Experience. J Tehran Heart Cent. 2010;5(2):87-91. Available from: http://jthc.tums.ac.ir/index.php/ithc/article/view/168

9. Femenía F, Arce M, Arrieta M, Palazzolo J, Trucco E. Long-term results of slow pathway ablation in patients with atrioventricular nodal reentrant tachycardia: simple approach. J Electrocardiol. 2012;45(3):203-8. Available from: https://doi. org/10.1016/i.jelectrocard.2011.12.007

10. Dagres N, Clague JR, Breithardt G, Borggrefe M. Significant gender-related differences in radiofrequency catheter ablation therapy. J Am Coll Cardiol. 2003;42(6):1103-7. Available from: https://doi.org/10.1016/S0735-1097(03)00925-2

11. Wood KA, Wiener CL, Kayser-Jones J. Supraventricular tachycardia and the struggle to be believed. Eur J Cardiovasc Nurs. 2007;6(4):293-302. Available from: https://doi.org/10.1016/i.ejcnurse.2007.02.006

12. Carnlöf C, Iwarzon M, Jensen-Urstad M, Gadler F, Insulander P. Women with PSVT are often misdiagnosed, referred later than men, and have more symptoms after ablation. Scand Cardiovasc J. 2017;51(6):299-307. Available from: https://doi. org/10.1080/14017431.2017.1385837

13. Lessmeier TJ, Gamperling D, Johnson-Liddon V, Fromm BS, Steinman RT, Meissner MD, Lehmann MH. Unrecognized paroxysmal supraventricular tachycardia. Potential for misdiagnosis as panic disorder. Arch Intern Med. 1997;157(5):537-43. Available from: https://doi.org/10.1001/archinte.1997.00440260085013

14. Liuba I, Jönsson A, Säfström K, Walfridsson H. Gender-related differences in patients with atrioventricular nodal reentry tachycardia. Am J Cardiol. 2006;97(3):384-8. Available from: https://doi.org/10.1016/j.amjcard.2005.08.042

15. Deneke T, Müller P, Lawo T, Lemke B, Horlitz M, Calcum B, Bösche LI, Mügge A, Grewe PH. Gender differences in onset of symptoms in $\mathrm{AV}$ nodal re-entrant and accessory pathway-mediated re-entrant tachycardia. Herzschrittmacherther Elektrophysiol. 2009;20(1):33-8. Available from: https://doi.org/10.1007/s00399-009-0036-7

16. Suenari K, Hu Y-F, Tso H-M, Tai C-T, Chiang C-E, Lin Y-J, et al. Gender Differences in the Clinical Characteristics and Atrioventricular Nodal Conduction Properties in Patients With Atrioventricular Nodal Reentrant Tachycardia. J Cardiovasc Electrophysiol. 2010;21(10):1114-9. Available from: https://doi.org/10.1111/i.1540-8167.2010.01779.x

17. Liu S, Yuan S, Hertervig E, Kongstad O, Olsson SB. Gender and atrioventricular conduction properties of patients with symptomatic atrioventricular nodal reentrant tachycardia and Wolff-Parkinson-White syndrome. J Electrocardiol. 2001;34(4):295-301. Available from: https://doi.org/10.1054/jelc.2001.26316

18. Rosenthal LS, Mahesh M, Beck TJ, Saul JP, Miller JM, Kay N, Klein LS, Huang S, Gillette P, Prystowsky E, Carlson M, Berger $\mathrm{RD}$, Lawrence JH, Yong $\mathrm{P}$, Calkins $\mathrm{H}$. Predictors of fluoroscopy time and estimated radiation exposure during radiofrequency catheter ablation procedures. Am J Cardiol. 1998;82(4):451-8. Available from: https://doi.org/10.1016/S00029149(98)00356-7 